\title{
Investigating hair zinc concentrations in children with and without atopic dermatitis
}

\author{
N A Gray, ${ }^{1,2}$ MB ChB; T M Esterhuizen, ${ }^{3}$ MSc; N P Khumalo, ${ }^{1,4}$ MB ChB, FC Derm (SA), PhD; D J Stein, ${ }^{2,5}$ FRCPC, PhD \\ ${ }^{1}$ Division of Dermatology, Groote Schuur Hospital and Faculty of Health Sciences, University of Cape Town, South Africa \\ ${ }^{2}$ Department of Psychiatry and Mental Health, Groote Schuur Hospital and Faculty of Health Sciences, University of Cape Town, South Africa \\ ${ }^{3}$ Division of Epidemiology and Biostatistics, Department of Global Health, Faculty of Medicine and Health Sciences, Stellenbosch University, \\ Cape Town, South Africa \\ ${ }^{4}$ Hair and Skin Research Laboratory, Division of Dermatology, Groote Schuur Hospital and Faculty of Health Sciences, University of Cape Town, \\ South Africa \\ ${ }^{5}$ South African Medical Research Council Risk and Resilience in Mental Disorders Unit, Department of Psychiatry, Faculty of Health Sciences, \\ University of Cape Town, South Africa
}

Corresponding author: N A Gray (nicolagrayemail@gmail.com)

\begin{abstract}
Background. Atopic dermatitis (AD) is a common chronic inflammatory skin condition that disproportionately affects children and is associated with reduced quality of life. Zinc deficiency may contribute to the pathogenesis of AD because zinc plays a role in epidermal barrier integrity and the immune system. Systematic review evidence suggests that low zinc is associated with $\mathrm{AD}$, but limitations of included studies support further investigation.

Objectives. To investigate hair zinc concentrations in children with $\mathrm{AD}$ v. healthy controls in a low- to middle-income country setting. Methods. One hundred and five children aged $1-12$ years participated in a frequency-matched for age case-control study. The outcome variable, $\mathrm{AD}$, was confirmed by a clinician and corroborated using the UK Working Party criteria. The primary predictor, long-term average zinc concentration, was determined by measuring hair zinc using inductively coupled mass spectrometry. Baseline demographic characteristics, anthropometry and measures of socioeconomic status were included in our logistic regression analysis. Subgroup analysis was performed where interaction terms suggested effect modification.

Results. Using data from the overall sample, population median hair zinc was not significantly different between children with $\mathrm{AD}$ and healthy controls. However, subgroup analysis suggested a clinically and statistically significant difference in median zinc between children with $\mathrm{AD}(175.35 \mu \mathrm{g} / \mathrm{g})$ and healthy controls $(206.4 \mu \mathrm{g} / \mathrm{g})$ in the older age group $(5-12$ years $)(p=0.01)$. In this age group, multivariable logistic regression analysis also found significantly decreased hair zinc concentrations in $\mathrm{AD}$ (odds ratio 0.83 ; $95 \%$ confidence interval $0.66-0.96 ; p=0.046)$.

Conclusions. The inverse association between zinc status and $\mathrm{AD}$ in children aged $5-12$ years in our setting is consistent with the international literature. The clinical importance of decreased zinc levels in $\mathrm{AD}$ is not yet known. Further investigation into relevant underlying mechanisms seems warranted given the global reach of $\mathrm{AD}$, its effect on quality of life, and the low cost of potential zinc-based interventions.
\end{abstract}

S Afr Med J 2020;110(5):409-415. https://doi.org/10.7196/SAMJ.2020.v110i5.14308

Atopic dermatitis (AD) is a chronic inflammatory skin condition that typically presents within the first 2 years of life..$^{[1]}$ The global prevalence in 6 - 7 -year-old children ranges from $0.9 \%$ to $22.5 \% .{ }^{[2]}$ Remissions and relapses occur, with $25 \%$ of cases persisting into adulthood. ${ }^{[3]}$ $\mathrm{AD}$ is associated with reduced quality of life. ${ }^{[4]}$ Intractable pruritus and sleep disturbance are characteristic symptoms and have been associated with psychological distress, behavioural problems and reduced school performance. ${ }^{[5]}$ Children with $\mathrm{AD}$ are at increased risk of developing allergic rhinitis and asthma. ${ }^{[3]} \mathrm{AD}$ has also been associated with an increase in non-allergic comorbid conditions including infections, psychiatric disorders (depression, anxiety, attention-deficit/hyperactivity disorder), obesity and cardiovascular disorders, among others, contributing to the high public health burden of the disease. ${ }^{[6]}$

Both skin barrier defects (the 'outside-in' hypothesis) and immunological alterations (the 'inside-out' hypothesis) contribute to the pathogenesis of $\mathrm{AD} \cdot{ }^{[7]} \mathrm{A}$ disrupted microbiota with reduced diversity and increased Staphylococcus aureus colonisation is also hypothesised to play a role. ${ }^{[8]}$ Zinc is an essential trace element, and low zinc levels may contribute to the pathogenesis of $\mathrm{AD}$ by all three of these mechanisms. First, low zinc levels may compromise epidermal barrier function. Zinc is required for proliferation and migration of keratinocytes in wound healing via ZnR/GPR-39, a keratinocyte G-protein-coupled receptor that responds to changes in extracellular zinc concentrations. ${ }^{[9]}$ Furthermore, a zinc finger transcription factor is required for $O V O L-1$ expression of filaggrin, an epidermal barrier protein implicated in the pathogenesis of AD. ${ }^{[10]}$ The zinc transporter, ZIP10, is also involved in regulation of genes required for epidermal homeostasis and barrier function. ${ }^{[11]}$ Second, low zinc levels may promote cutaneous inflammation. An AD-like eruption can be induced in $D S-N h$ mice by a zinc-deficient diet. This eruption is associated with altered immune profiles, including increased production of the atopy-associated proinflammatory Th-2 cytokines. ${ }^{[12]}$ Conversely, application of topical zinc oxide to damaged skin has anti-inflammatory effects. ${ }^{[13]}$ Third, low zinc levels may promote S. aureus colonisation. Although the relationship between total body zinc and cutaneous $S$. aureus activity is not known, zinc oxide nanoparticles have in vitro activity against $S$. aureus. ${ }^{[14]}$ 
Furthermore, in the abovementioned DS-Nh mouse model of AD, zinc deficiency was also associated with increased $S$. aureus colonisation. ${ }^{[12]}$

A systematic review and meta-analysis of observational studies suggests that low zinc (as measured in serum, erythrocytes and hair) is associated with $\mathrm{AD} .{ }^{[15]}$ However, owing to limitations of included studies, further investigation is needed. Furthermore, previous studies are primarily from upper middle-income countries (UMICs) and high-income countries (HICs), and results are not necessarily generalisable to low- to middle-income country (LMIC) settings. The zinc-AD relationship has not been studied previously in the South African (SA) context, where the prevalence of $\mathrm{AD}$ is increasing and zinc deficiency remains a concern, despite mandatory fortification of maize and wheat flour. ${ }^{[16,17]}$

\section{Objectives}

To perform a case-control study to investigate hair zinc concentrations in children with $\mathrm{AD}$ v. healthy controls.

\section{Methods}

\section{Case selection}

Sequential children presenting with $\mathrm{AD}$ to a specialised outpatient dermatology service at Red Cross War Memorial Children's Hospital (RCWMCH), Cape Town, SA, were approached for potential inclusion into the study. Predefined inclusion criteria included age $1-12$ years and corroboration of the clinical diagnosis of $\mathrm{AD}$ using the $\mathrm{UK}$ Working Party criteria. ${ }^{[1]}$ Exclusion criteria were acute illness, nonallergic comorbid chronic disease, infected $\mathrm{AD}$, inadequate scalp hair for sampling, and use of multivitamins or zinc supplements within the past 3 months. The study was approved by the University of Cape Town Human Research Ethics Committee (ref. no. HREC 473/2017), and informed consent was obtained from primary caregivers.

\section{Control selection}

Healthy controls were frequency-matched for age only. Adults accompanying children aged $<5$ years (excluding those aged $<1$ year) were approached in clinic waiting rooms during the school holidays. These children were mainly friends or family of patients attending various medical, surgical and dental outpatient clinics at RCWMCH. In addition to the abovementioned exclusion criteria, controls had no history of atopic or allergic disease and were not first-degree relatives of cases.

Because there were few healthy controls aged $\geq 5$ years in clinic waiting rooms, controls aged 5 - 12 years were recruited from a local school. Class teachers were informed of the eligibility criteria and were asked to choose the required number of children by drawing names of eligible children from a hat. The research team visited the school on a subsequent day to collect data from children whose parents had provided informed consent.

\section{Baseline demographic characteristics}

Data were collected on age, sex and frequency of hair washing. All participants were weighed and measured. Weight and length/height measurements were converted to age-appropriate World Health Organization (WHO) $z$-scores: weight for length (age $1-2$ years), weight for height ( $2-5$ years) and body mass index (BMI) for age ( $\geq 5$ years).

\section{Clinical characteristics}

The SCORing for Atopic Dermatitis (SCORAD) instrument was completed for all cases by the same clinician (NAG) ${ }^{[18]}$ The Children's Dermatology Life Quality Index (CDLQI) was used for all children aged $>5$ years. ${ }^{[19]}$ The question on swimming in the CDLQI was omitted, as few children had regular access to swimming pools. Use of medication was documented, and it was confirmed that children had not taken any zinc-containing supplements during the preceding 3 months.

\section{Socioeconomic status}

A socioeconomic status questionnaire for caregivers was designed based on the National Income Dynamics Survey. ${ }^{[20]}$ This survey was chosen because of its appropriateness for the SA context and local validation. Three variables were derived from these data: primary caregiver school years completed, household income indicator (midpoint of the participant's household income bracket), and number of people in the household.

\section{Hair zinc analysis}

Zinc status was assessed using hair zinc measurements. This method was selected because it is less invasive than measuring serum or erythrocyte zinc. Furthermore, hair grows at an average of $1 \mathrm{~cm}$ per month, and analysis of proximal hair segments may therefore give an indication of average zinc levels over a longer period (e.g. 3 months for $3 \mathrm{~cm}$ hair), rather than zinc levels at a random single point in time. Hair zinc may be a better marker of marginal zinc deficiency than serum zinc, perhaps because the slow uptake of zinc by the hair is preferentially reduced in states of decreased zinc availability. ${ }^{[21]}$

Hair was collected from the posterior vertex and cut as close to the scalp as possible using a standard protocol. Samples were stored in paper envelopes at room temperature before processing at the University of Cape Town Hair and Skin Laboratory. Only the proximal $3 \mathrm{~cm}$ of hair was used, and hair was cut using ceramic scissors. Ten milligram aliquots of hair were placed in a Pyrex beaker and washed for 10 minutes in each of the following, in order: acetone, methanol and deionised water. The samples were air-dried overnight. Ten millilitres of 65\% Suprapur Nitric Acid (Sigma-Aldrich, Germany) was added to each sample in Teflon. Samples then underwent microwave digestion using a MARS 6 instrument (CEM Corp., USA) for 30 minutes at $200^{\circ} \mathrm{C} .{ }^{[22]}$ After cooling, digested samples were filtered using $0.45 \mu \mathrm{m}$ syringe filters and stored in a fridge $\left(-4--6^{\circ} \mathrm{C}\right)$. All samples (including 10 blanks, prepared using the same protocol but omitting the hair) were then transported to the Stellenbosch University Central Analytical Facilities, where they underwent a 7-times dilution prior to analysis on an Agilent 7900 ICP-MS quadrupole mass spectrometry system (Agilent, USA).

\section{Statistical analysis}

As the distribution of hair zinc concentrations was skewed to the right, differences between groups were analysed using non-parametric Mann-Whitney $U$-tests. Effect sizes for the Mann-Whitney $U$-test were calculated using the $r$ statistic $(0<r<1) .^{[23]}$ Univariate and multivariable logistic regression models were fitted, with odds of $\mathrm{AD}$ as the outcome variable. The interaction of age and zinc was a significant predictor of $\mathrm{AD}$, suggesting effect modification. Subgroup analysis according to age group ( $\geq 1-<5$ years and $5-12$ years) was therefore performed. Variables with $p<0.1$ in the univariate subgroup analyses were identified as potential confounders and were therefore adjusted for in the multivariable models. Results are reported as odds ratios (ORs) with $95 \%$ confidence intervals (CIs), and $p<0.05$ was used as the cut-off for statistical significance. The final models were also repeated using multiple imputation for participants with missing socioeconomic status variables $(\leq 10 \%)$ to confirm consistent 
results. Analyses were performed using R version 3.6.0 (R Core Team, Austria), using the following packages: base, stats, rcompanion, mice, graphics and ggplot2.

\section{Results}

\section{Baseline demographic characteristics}

One hundred and five children (AD and controls) participated in our case-control study investigating the association between zinc status and AD. Participant characteristics are presented in Table 1. Of the children, $51 \%$ were aged $\geq 1-<5$ years and $49 \% 5-12$ years. Fifty-nine percent were female. Ninety-four percent of children aged $\geq 1-<5$ years and $96 \%$ of children aged $5-12$ years had WHO anthropometry scores within two standard deviations (SDs) of the mean. No child was found to be underweight. Fifty-seven percent of children washed their hair less than three times a week, with similar findings between cases and controls (57\% and 56\%, respectively).

\section{Clinical characteristics}

According to the SCORAD instrument, $90 \%$ of participants had moderate or severe $\mathrm{AD}$, with only $10 \%$ falling in the mild category. Similarly, the median (interquartile range (IQR)) CDLQI score was 17.5 (15 - 21.8), with the maximum possible adverse quality of life represented by a score of 27 .

\section{Socioeconomic status}

The median household income indicator in the overall sample was ZAR4 500 ( USD318 or EUR283 at the time of writing) per month. ${ }^{[24]}$ The median household income indicator was significantly higher in controls (ZAR8 500) compared with cases (ZAR4 500).
The median (IQR) number of people permanently residing in the household was 5 (4-6), and the median number of caregiver school years completed was 12. As shown in Table 1 , in contrast to the median household income indicator, the latter two socioeconomic variables did not differ greatly between cases and controls.

\section{Comparison of hair zinc between participants with $\mathrm{AD}$ and controls}

The distribution of hair zinc concentrations was skewed to the right (Fig. 1). For the overall sample, the median zinc concentration was $176.78 \mu \mathrm{g} / \mathrm{g}$. Twenty-one of the 105 participants (20\%) had a hair zinc concentration $<130 \mu \mathrm{g} / \mathrm{g}$, and none had a concentration $<70 \mu \mathrm{g} / \mathrm{g}$.

As shown in Table 2, there was no significant difference in median zinc concentration in participants with $\mathrm{AD}$ v. controls (164.86 v. $189.62 \mu \mathrm{g} / \mathrm{g} ; p=0.1$ ). When participants were stratified by age, there was similarly no significant difference in median zinc concentration between participants with AD v. controls in the younger children aged $\geq 1$ - $<5$ years $(142.94$ v. $152.44 \mu \mathrm{g} / \mathrm{g} ; p=0.53)$. However, there was a statistically significant lower median zinc concentration in participants with AD v. controls in the older children aged 5 - 12 years $(175.35 \mathrm{v}$. $206.4 \mu \mathrm{g} / \mathrm{g} ; p=0.01)$. There was a small effect size for the overall sample $(r=0.16)$ and the younger children $(r=0.09)$, with a medium effect size for the older children $(r=0.35)$. A visual representation of these data is provided using box-and-whisker plots in Figs 2 and 3.

\section{Association between hair zinc concentration and odds of $\mathrm{AD}$}

In the overall sample, univariate analysis did not show a significant association between hair zinc concentration and AD (OR 0.96;

\begin{tabular}{|c|c|c|c|}
\hline Characteristic & Total $(N=105)$ & $\mathrm{AD}(N=40)$ & No AD $(N=65)$ \\
\hline \multicolumn{4}{|l|}{ Age (years), $n(\%)$} \\
\hline$\geq 1-<5$ & $54(51.4)$ & $20(50.0)$ & $34(52.3)$ \\
\hline $5-12$ & $51(48.6)$ & $20(50.0)$ & $31(47.7)$ \\
\hline Female sex, $n(\%)$ & $59(56.2)$ & $21(52.5)$ & $38(58.5)$ \\
\hline \multicolumn{4}{|l|}{ WHO weight for length/height ( $<5$ years), $n(\%)$} \\
\hline Within 2 SD of mean & $51 / 54(94.4)$ & $18 / 20(90.0)$ & $33 / 34(97.1)$ \\
\hline$>2 \mathrm{SD}$ of mean & $3 / 54(5.6)$ & $2 / 20(10.0)$ & $1 / 34(2.9)$ \\
\hline$<2 \mathrm{SD}$ of mean & 0 & 0 & 0 \\
\hline \multicolumn{4}{|l|}{ WHO BMI for age ( 5 - 12 years), $n(\%)$} \\
\hline Within 2 SD of mean & $49 / 51(96.1)$ & $20 / 20(100)$ & $29 / 31(93.5)$ \\
\hline$>2 \mathrm{SD}$ of mean & $2 / 51(3.9)$ & 0 & $2 / 31(6.5)$ \\
\hline$<2 \mathrm{SD}$ of mean & 0 & 0 & 0 \\
\hline \multicolumn{4}{|l|}{ Hair wash frequency (times per week), $n(\%)$} \\
\hline$<3$ & $59 / 104(56.7)$ & $23 / 40(57.5)$ & $36 / 64(56.3)$ \\
\hline$\geq 3$ & $45 / 104(43.3)$ & $17 / 40(42.5)$ & $28 / 64(43.8)$ \\
\hline \multicolumn{4}{|l|}{ SCORAD category, $n(\%)$} \\
\hline Mild & - & $4 / 40(10.0)$ & - \\
\hline Moderate & - & $10 / 40(25.0)$ & - \\
\hline Severe & - & $26 / 40(65.0)$ & - \\
\hline \multicolumn{4}{|l|}{ CDLQI } \\
\hline Median (IQR) & - & $17.5(15-21.8)$ & - \\
\hline Mean (SD) & - & $18.3(5.3)$ & - \\
\hline Household income indicator (ZAR), median (IQR) & $4500(2250-8500)$ & $4500(2250-8500)$ & $8500(2812-19000)$ \\
\hline People permanently living in the household $(n)$, median (IQR) & $5(4-6)$ & $4(4-5)$ & $5(4-6)$ \\
\hline School years completed, median (IQR) & $12(11-12)$ & $12(11-12)$ & $12(11-12)$ \\
\hline
\end{tabular}


95\% CI 0.90 - 1.00; $p=0.12$ ) (Table 3). However, the interaction of age and zinc was a significant predictor of $\mathrm{AD}$ $(p=0.02)$, suggesting effect modification, and subgroup analysis by age category was therefore undertaken.

Subgroup analysis by age category (Table 4) showed that a higher hair zinc

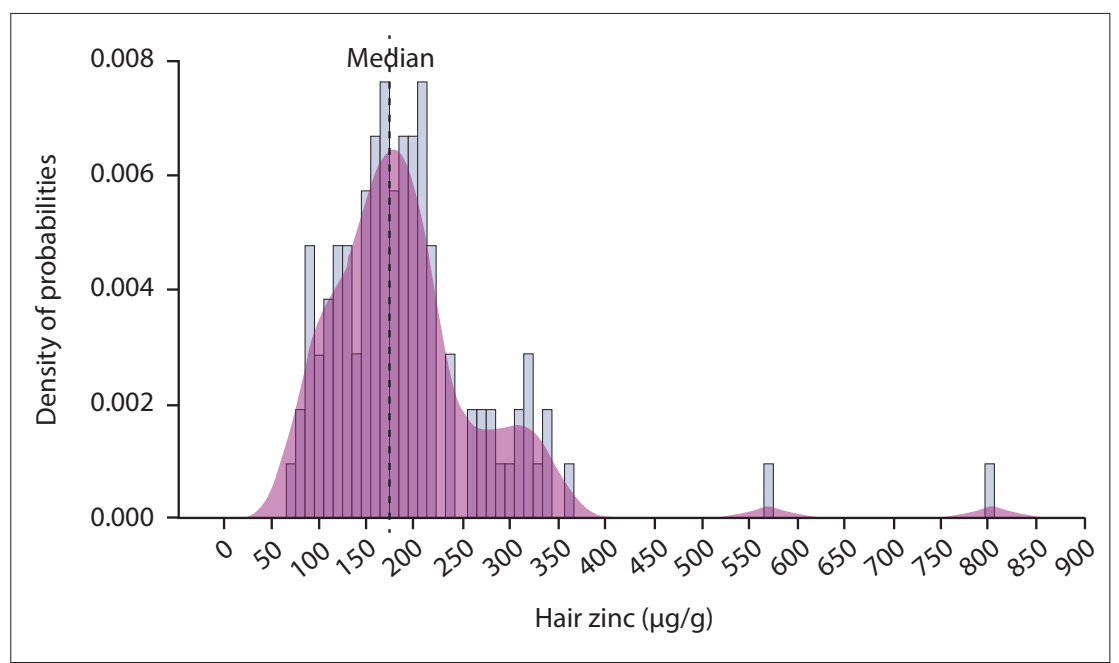

Fig. 1. Distribution of hair zinc concentrations in the overall sample $(\mathrm{N}=105)$.

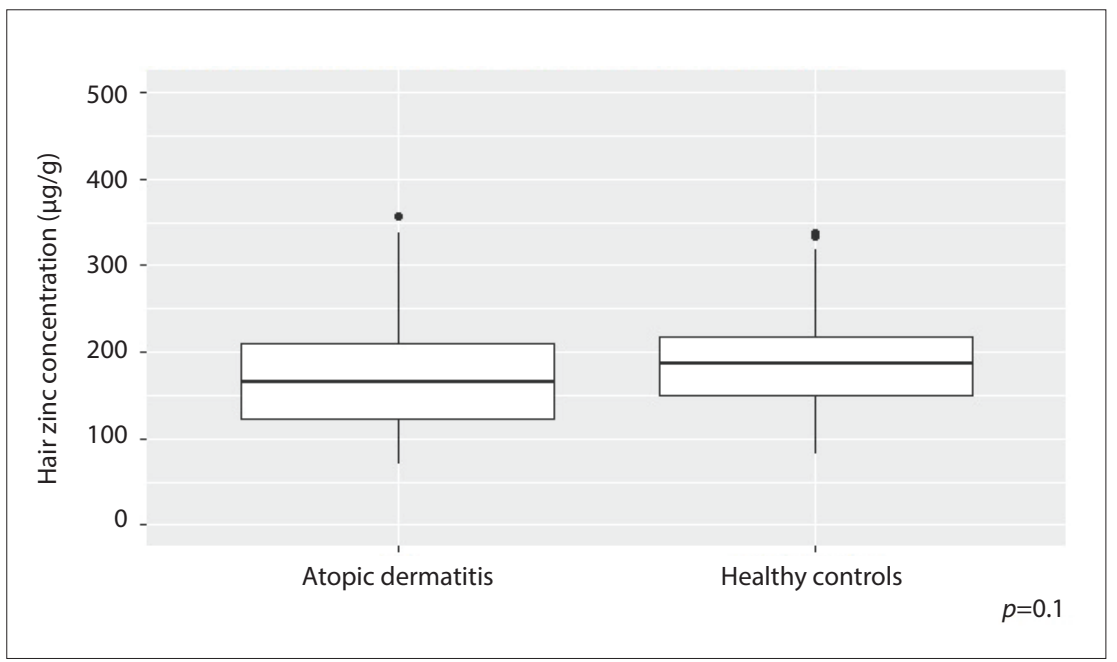

Fig. 2. Comparison of hair zinc in children: overall sample $(\mathrm{N}=105)$.

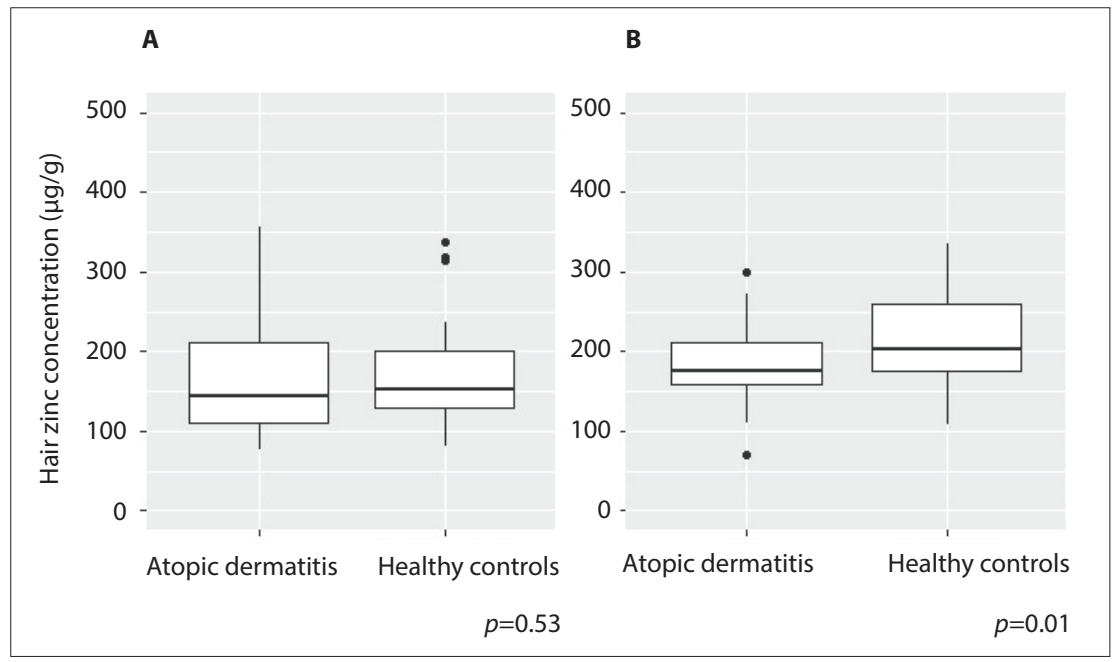

Fig. 3. Comparison of hair zinc stratified by age group: (A) children aged $<5$ years $(\mathrm{n}=54)$, (B) children aged 5 - 12 years $(\mathrm{n}=51)$. concentration was significantly associated with decreased odds of $\mathrm{AD}$ in older children (aged 5 - 12 years) (OR 0.87; 95\% CI $0.75-0.97 ; p=0.03)$, but not in younger children ( $\geq 1-<5$ years) (OR 0.99; 95\% CI 0.92 - 1.04; $p=0.62)$. Anthropometric characteristics, caregiver education and household income indicator were identified as potential confounders $(p<0.1$ in subgroup univariate analyses). As shown in Table 5, multivariable analysis adjusting for these confounders confirmed that higher hair zinc concentration was still associated with a significantly decreased odds of $\mathrm{AD}$ in children aged 5 - 12 years (OR 0.83; 95\% CI 0.66 - 0.96; $p=0.046)$. Put differently, in children aged 5-12 years, for every $10 \mu \mathrm{g} / \mathrm{g}$ increase in hair zinc, the odds of $\mathrm{AD}$ decreased by $17 \%$ after adjusting for anthropometric characteristics, caregiver education and household income. Repeating the analysis using multiple imputation for 8 participants with missing socioeconomic data points yielded comparable results (OR 0.81; 95\% CI $0.65-0.95 ; p=0.007$ ) (Table 6).

\section{Discussion}

The objective of this study was to investigate the association between hair zinc and AD in children in an LMIC context. We found higher median hair zinc concentrations in cases v. controls, but this was only statistically significant in older children (5 12 years of age). Similarly, in our logistic regression analysis, we found a significant interaction between age and zinc in predicting the outcome of AD. Multivariable analysis confirmed that increasing hair zinc concentrations were significantly associated with decreased odds of $\mathrm{AD}$ in children aged 5 - 12 years, even after adjusting for potential confounders (OR 0.83; 95\% CI 0.66 - 0.96; $p=0.046$ ).

Analysing proximal hair segments for zinc concentration gives a useful indication of average hair zinc levels, with $1 \mathrm{~cm}$ of scalp hair correlating to $\sim 1$ month of growth. Limiting analysis to the proximal $3 \mathrm{~cm}$ also reduces the risk of a potential 'washout effect', although this effect may not be a significant consideration in hair zinc analysis, unlike other substances. ${ }^{[25]}$ Assessment of average zinc levels, rather than serum or erythrocyte zinc, is also useful considering that zinc is not stored in the body and regular dietary intake is therefore necessary. ${ }^{[26]}$ It has also been suggested that hair zinc may be more sensitive in detecting marginal zinc deficiency. ${ }^{[21]}$

Three other published studies report reduced hair zinc concentrations in partici- 
Table 2. Comparison of hair zinc $(\mu \mathrm{g} / \mathrm{g})$ by age and AD status

\begin{tabular}{|c|c|c|c|c|c|}
\hline Patient group & Total & $\mathrm{AD}$ & No AD & $p$-value ${ }^{\dagger}$ & Effect size $(r)$ \\
\hline Children $<5$ years, median (IQR) & $152.44(118.03-204.64)$ & $142.94(109.73-212.08)$ & $152.44(129.12-201.78)$ & 0.53 & 0.09 \\
\hline Children 5 - 12 years, median (IQR) & $190.06(168.61-230.50)$ & $175.35(159.01-210.21)$ & $206.4(176.1-267.6)$ & $0.01^{*}$ & $0.35^{\ddagger}$ \\
\hline Overall children, median (IQR) & $176.78(138.18-219.71)$ & $164.86(123.54-210.21)$ & $189.62(150.71-222.12)$ & 0.10 & 0.16 \\
\hline
\end{tabular}

Table 3. Univariate logistic regression analysis with outcome $y=p(\mathrm{AD})$ using overall sample

\begin{tabular}{|c|c|c|c|c|c|}
\hline Variable & $n$ & Estimate & OR & 95\% CI of OR & $p$-value \\
\hline Zinc (per $10 \mu \mathrm{g} / \mathrm{g}$ increment) & 105 & -0.04 & 0.96 & $0.90-1.00$ & 0.12 \\
\hline Age (years) & 105 & 0.0005 & 1.00 & $0.89-1.12$ & 0.99 \\
\hline Age category & 105 & 0.09 & 1.10 & $0.50-2.42$ & 0.82 \\
\hline Male sex & 105 & 0.24 & 1.27 & $0.57-2.82$ & 0.55 \\
\hline Anthropometry score & 105 & -0.10 & 0.91 & $0.61-1.33$ & 0.62 \\
\hline Education (caregiver school years completed) & 100 & -0.12 & 0.87 & $0.62-1.27$ & 0.51 \\
\hline Household income indicator (ZAR) & 94 & -0.05 & 0.9999 & $0.9998-0.99998$ & $0.02^{*}$ \\
\hline Number of household members & 100 & -0.12 & 0.88 & $0.70-1.10$ & 0.28 \\
\hline Age $\times$ zinc & 105 & -0.003 & 0.997 & $0.99-0.999$ & $0.02^{*}$ \\
\hline Household income indicator $\times$ zinc & 94 & -0.01 & 0.999999 & $0.999998-1.000000$ & 0.20 \\
\hline
\end{tabular}

Table 4. Subgroup analysis: Univariate logistic regression analysis with outcome $y=p(\mathrm{AD})$ stratified by age

\begin{tabular}{|c|c|c|c|c|c|c|c|c|c|c|}
\hline \multirow[b]{2}{*}{ Variable } & \multicolumn{5}{|c|}{ Age $\geq 1-<5$ years } & \multicolumn{5}{|c|}{ Age 5 - 12 years } \\
\hline & $n$ & Estimate & OR & $95 \%$ CI of OR & $p$-value & $n$ & Estimate & OR & $95 \%$ CI of OR & $p$-value \\
\hline $\begin{array}{l}\text { Zinc (per } 10 \mu \mathrm{g} / \mathrm{g} \\
\text { increment) }\end{array}$ & 54 & -0.01 & 0.99 & $0.92-1.04$ & 0.62 & 51 & -0.14 & 0.87 & $0.75-0.97$ & 0.03 \\
\hline Male sex & 2 & 0.48 & 1.62 & $0.53-5.01$ & 0.40 & 51 & -0.01 & 0.99 & $0.32-3.09$ & 0.99 \\
\hline Anthropometry score & 54 & 0.50 & 1.65 & $0.95-3.02$ & $0.09^{* 1}$ & 51 & -0.80 & 0.45 & $0.20-0.85$ & $0.03^{*}$ \\
\hline $\begin{array}{l}\text { Education (caregiver school } \\
\text { years completed) }\end{array}$ & 53 & 0.13 & 1.14 & $0.73-1.85$ & 0.59 & 47 & -1.60 & 0.74 & $0.03-0.65$ & $0.03^{*}$ \\
\hline $\begin{array}{l}\text { Household income } \\
\text { indicator (ZAR) }\end{array}$ & 50 & -0.03 & 0.99995 & $0.9998-1.00$ & 0.48 & 44 & -0.03 & 0.9999 & $0.9997-0.99995$ & $0.01^{\star}$ \\
\hline $\begin{array}{l}\text { Number of household } \\
\text { members }\end{array}$ & 53 & -0.22 & 0.80 & $0.56-1.08$ & 0.18 & 47 & -0.01 & 0.99 & $0.70-1.38$ & 0.97 \\
\hline $\begin{array}{l}\text { Income per person } \\
\text { indicator (ZAR) }\end{array}$ & 50 & 0.01 & 1.00 & $0.999-1.00$ & 0.94 & 42 & -0.0004 & 0.9996 & $0.999-0.9999$ & $0.04^{*}$ \\
\hline
\end{tabular}

Table 5. Subgroup analysis: Multivariate logistic regression analysis with outcome $y=p(\mathrm{AD})$ stratified by age group

\begin{tabular}{|c|c|c|c|c|c|c|c|c|}
\hline \multirow[b]{2}{*}{ Variable } & \multicolumn{4}{|c|}{ Age $\geq 1-<5$ years $(n=50)$} & \multicolumn{4}{|c|}{ Age 5 - 12 years $(n=43)$} \\
\hline & Estimate & OR & $95 \%$ CI of OR & $p$-value & Estimate & OR & $95 \% \mathrm{CI}$ of $\mathrm{OR}$ & $p$-value \\
\hline Zinc (per $10 \mu \mathrm{g} / \mathrm{g}$ increment) & -0.04 & 0.96 & $0.89-1.02$ & 0.28 & -0.19 & 0.83 & $0.66-0.96$ & $0.046^{*}$ \\
\hline Anthropometry score & 0.52 & 1.68 & $0.90-3.36$ & 0.12 & -0.81 & 0.44 & $0.15-1.04$ & 0.09 \\
\hline $\begin{array}{l}\text { Education (caregiver school years } \\
\text { completed) }\end{array}$ & 0.08 & 1.09 & $0.67-1.85$ & 0.75 & -1.01 & 0.37 & $0.03-1.28$ & 0.22 \\
\hline Household income indicator (ZAR) & -0.00008 & 0.9999 & $0.9997-1.00$ & 0.33 & -0.0002 & 0.9998 & $0.9997-0.99996$ & $0.03^{*}$ \\
\hline
\end{tabular}

pants with AD v. controls. The first, a study of Italian children aged 2 - 14 years published in 1987, ${ }^{[27]}$ reported a mean (SD) hair zinc concentration of 99 (10) v. 147 (9) $\mu \mathrm{g} / \mathrm{g}$ in participants with AD v. controls $(p<0.05)$. The second, a study of Egyptian children aged
2 - 10 years published in $1990,{ }^{[28]}$ reported a mean (SD) hair zinc concentration of 164.8 (23.6) v. 194.5 (18.6) $\mu \mathrm{g} / \mathrm{g}$ in participants with AD v. controls $(p<0.001)$. The third, a study of South Korean children aged 2 - 14 years published in $2014,{ }^{[29]}$ reported a mean (SD) hair zinc 
Table 6. Subgroup analysis: Multivariate logistic regression analysis with outcome $y=p(\mathrm{AD})$ stratified by age group and using multiple imputation

\begin{tabular}{|c|c|c|c|c|c|c|c|c|}
\hline \multirow[b]{2}{*}{ Variable } & \multicolumn{4}{|c|}{ Age $\geq 1-<5$ years $(n=54)$} & \multicolumn{4}{|c|}{ Age 5 - 12 years $(n=51)$} \\
\hline & Estimate & OR & $95 \% \mathrm{CI}$ of OR & $p$-value & Estimate & OR & $95 \%$ CI of OR & $p$-value \\
\hline Zinc (per $10 \mu \mathrm{g} / \mathrm{g}$ increment) & -0.03 & 0.97 & $0.91-1.03$ & 0.28 & -0.21 & 0.81 & $0.65-0.95$ & $0.007^{\star *}$ \\
\hline Anthropometry score & 0.59 & 1.81 & $1.00-3.52$ & 0.06 & -0.92 & 0.40 & $0.14-0.92$ & 0.05 \\
\hline $\begin{array}{l}\text { Education (caregiver school } \\
\text { years completed) }\end{array}$ & 0.09 & 1.10 & $0.68-1.85$ & 0.71 & -1.12 & 0.33 & $0.02-1.19$ & 0.21 \\
\hline $\begin{array}{l}\text { Household income indicator } \\
\text { (ZAR) }\end{array}$ & -0.0001 & 0.9999 & $0.9997-1.00$ & 0.23 & -0.0001 & 0.9999 & $0.9997-0.99997$ & $0.04^{*}$ \\
\hline
\end{tabular}

concentration of $113.10(33.36)$ v. 130.9 (36.63) $\mu \mathrm{g} / \mathrm{g}$ in participants with $\mathrm{AD}$ v. controls $(p=0.012)$. Interestingly, in all these studies, average zinc levels were significantly lower in children with $A D$ across the age spectrum, even though all included children aged $<5$ years. Subgroup analysis by age was not indicated or performed. The lack of a statistically significant difference in hair zinc in the younger children ( $\geq 1-<5$ years) in our study is therefore new.

Publication bias is one potential reason why the null association in younger children has not been reported previously, but there are several other possibilities. First, zinc deficiency may be more relevant to older children because of a different AD molecular phenotype. This hypothesis is based on findings of differing age-related molecular phenotypes in adult $\mathrm{AD}$, but relevance to persons aged $<18$ years and relevance to zinc metabolism are not yet known. ${ }^{[30]}$ Second, our findings may reflect failure to reject a false null hypothesis (type II statistical error). Third, the difference in zinc levels between children with $\mathrm{AD}$ and healthy children may be attenuated by the effects of the mandatory food fortification programme in SA. Dietary practices may also vary by age, with older children consuming lower proportions of zinc-rich or zinc-fortified foods relative to their ageappropriate dietary requirements. Fourth, children aged $<5$ years attending RCWMCH benefit from good uptake of routine growth monitoring and nutritional health promotion via the Road to Health booklet, thus mitigating the risk of relative zinc deficiency in this group. This protective effect may not extend to older children, as the focus of the Road to Health booklet is the first 5 years of life. ${ }^{[31]}$

Several other studies have used erythrocyte or serum zinc measures to compare participants with $\mathrm{AD}$ with controls. Meta-analysis confirmed overall reduced zinc across eight studies analysing serum zinc in $\mathrm{AD}$ v. controls (standardised mean difference 0.66; 95\% CI $0.21-1.10 ; p=0.004){ }^{[15]}$ Similarly, two studies of erythrocyte zinc showed lower concentrations in participants with $A D \mathrm{v}$. controls. ${ }^{[32,33]}$ Of note, most of the studies originated from UMIC or HIC settings. ${ }^{[15]}$ An exception is a study from Bangladesh, ${ }^{[34]}$ reporting a mean $(\mathrm{SD})$ serum zinc concentration of $0.30(0.02)$ $\mathrm{mg} / \mathrm{L}$ in participants with $\mathrm{AD}$ v. $0.02(0.06) \mathrm{mg} / \mathrm{L}$ in healthy controls $(p<0.001)$. Participant age ranged from 15 to 35 years, therefore representing an older age group than that in our study.

The clinical significance of the association between low zinc levels and $\mathrm{AD}$ has yet to be elucidated. Some authors have suggested hair zinc concentrations $<70$ or $<130 \mu \mathrm{g} / \mathrm{g}$ as cut-offs for zinc deficiency. ${ }^{[21,35]}$ No children in our sample had a hair zinc concentration $<70 \mu \mathrm{g} / \mathrm{g}$, and $20 \%$ of our sample had concentrations $<130 \mu \mathrm{g} / \mathrm{g}$. However, as there are no locally or internationally validated reference ranges for hair zinc concentrations, these findings should be interpreted with caution. Furthermore, the level of zinc deficiency required to contribute clinically to $\mathrm{AD}$ symptoms is not known and may differ from normal reference ranges. Clinically significant zinc thresholds may also differ by age, in line with evidence suggesting that normal total body zinc levels increase with age during childhood. ${ }^{[21,36]}$ Our data are therefore useful in confirming a statistically significant difference in hair zinc in children aged 5 - 12 years in an LMIC setting, but further study is required to prove clinical significance. One such approach would be randomised controlled trials of zinc supplementation in AD. Two such studies have previously been undertaken, but methodological limitations, different outcome measures and conflicting results make interpretation difficult. ${ }^{[15]}$

\section{Study limitations}

Some of the strengths and limitations of our study have already been mentioned. Further limitations include the risk of selection bias, particularly regarding different selection of controls for participants in different age categories, and the relatively small sample size $(N=105)$. Because we did not measure zinc levels prior to establishing the outcome, we cannot be sure that reverse causality is not the explanation for our findings. However, as we indicated earlier, there is other evidence to support the hypothesis that low zinc levels may be causally related to expression of AD. Furthermore, our conclusions are drawn from a subgroup analysis. We do not know whether we would have found the same association in younger children if we had sourced younger controls from the general population, instead of in hospital waiting room areas.

Despite the above limitations, our study has several strengths. First, the outcome of interest, $\mathrm{AD}$, was confirmed by a clinician and corroborated using independent criteria. Second, a detailed description of controls is provided, which was missing from earlier publications. Third, few have investigated the zinc-AD relationship in LMIC settings, and to our knowledge none have done so in sub-Saharan Africa.

\section{Conclusions}

Consistent with the international literature, our study showed an inverse association between zinc status and $\mathrm{AD}$ in older children (aged 5 - 12 years). While the role of total body zinc concentrations in the complex aetiopathogenesis of $\mathrm{AD}$ is likely to be small, it needs to be considered in the context of the global reach of $\mathrm{AD}$, its profound effect on childhood morbidity, and the low cost of potential zinc supplementation. Further research into the underlying mechanisms of lower zinc levels in $\mathrm{AD}$, and whether these inform treatment targets, is therefore warranted.

Declaration. The research for this study was done in partial fulfilment of the requirements for NAG's PhD degree at the University of Cape Town. Acknowledgements. The authors thank enrolled nurse Juliet Esterhuizen for assistance with data collection. 
Author contributions. NAG conceptualised the study and proposed the initial study design, collected data from participants, assisted with preliminary laboratory work, performed the statistical analysis and wrote the first draft of the article. TME provided expert guidance on statistical analysis and interpretation of findings. NPK assisted with refining the study design, facilitated data collection and led the processing of hair samples for zinc concentration. DJS assisted with refining the study design and facilitated data collection. All authors contributed to manuscript revisions and approved the final draft for submission.

Funding. NAG is funded by a Discovery Foundation Academic Fellowship Award. DJS is funded by the South African Medical Research Council (SAMRC). NPK is funded by the National Research Foundation and the SAMRC

\section{Conflicts of interest. None.}

1. Williams HC, Burney PG, Pembroke AC, Hay RJ. The U.K. Working Party's Diagnostic Criteria for Atopic Dermatitis. III. Independent hospital validation. Br J Dermatol 1994;131(3):406-416. https:// doi.org/10.1111/j.1365-2133.1994.tb08532.x

2. Odhiambo JA, Williams HC, Clayton TO, Robertson CF, Asher MI. Global variations in prevalence of eczema symptoms in children from ISAAC Phase Three. J Allergy Clin Immunol 2009;124(6):12511258.e1223. https://doi.org/10.1016/j.jaci.2009.10.009

3. Thomsen SF. Atopic dermatitis: Natural history, diagnosis, and treatment. Allergy 2014;2014:354250. https://doi.org/10.1155/2014/354250

4. Olsen JR, Gallacher J, Finlay AY, Piguet V, Francis NA. Quality of life impact of childhood skin conditions measured using the Children’s Dermatology Life Quality Index (CDLQI): A meta-analysis. Br J Dermatol 2016;174(4):853-861. https://doi.org/10.1111/bjd.14361

5. Blume-Peytavi U, Metz M. Atopic dermatitis in children: Management of pruritus. J Eur Acad Dermatol Venereol 2012;26( Suppl 6):2-8. https://doi.org/10.1111/j.1468-3083.2012.04710.x

6. Silverberg JI. Public health burden and epidemiology of atopic dermatitis. Dermatol Clin 2017;35(3):283-289. https://doi.org/10.1016/j.det.2017.02.002
6ilverberg JI. Public health burde and epidemiology

7. Wang D, Beck LA. Immunologic targets in atopic dermatitis and emerging therapies: An update. Am J Wang D, Beck LA. Immunologic targets in atopic dermatitis and emerging ther
Clin Dermatol 2016;17(5):425-443. https://doi.org/10.1007/s40257-016-0205-5

8. Geoghegan JA, Irvine AD, Foster TJ. Staphylococcus aureus and atopic dermatitis: A complex and evolving relationship. Trends Microbiol 2018;26(6):484-497. https://doi.org/10.1016/j.tim.2017.11.008 9. Hershfinkel M. The zinc sensing receptor, ZnR/GPR39, in health and disease. Int J Mol Sci 2018;19(2):439. https://doi.org/10.3390/ijms19020439

10. Tsuji G, Ito T, Chiba T, et al. The role of the OVOL1-OVOL2 axis in normal and diseased human skin. J Dermatol Sci 2018;90(3):227-231. https://doi.org/10.1016/j.jdermsci.2018.02.005

11. Bin $\mathrm{BH}$, Lee $\mathrm{SH}$, Bhin J, et al. The epithelial zinc transporter ZIP10 epigenetically regulates human epidermal homeostasis by modulating histone acetyltransferase activity. $\mathrm{Br} \mathrm{J}$ Dermatol 2019;180(4):869-880. https://doi.org/10.1111/bjd.17339

12. Takahashi $\mathrm{H}$, Nakazawa $M$, Takahashi $K$, et al. Effects of zinc deficient diet on development of atopic dermatitis-like eruptions in DS-Nh mice. J Dermatol Sci 2008;50(1):31-39. https://doi.org/10.1016/j. jdermsci.2007.11.002

13. Maarouf M, Vaughn AR, Shi VY. Topical micronutrients in atopic dermatitis - an evidence-based review. Dermatol Ther 2018;31(5):e12659. https://doi.org/10.1111/dth.12659

14. Kadiyala U, Turali-Emre ES, Bahng JH, Kotov NA, VanEpps JS. Unexpected insights into antibacterial Kadiyala U, Turali-Emre ES, Bahng JH, Kotov NA, VanEpps JS. Unexpected insights into antibacterial
activity of zinc oxide nanoparticles against methicillin resistant Staphylococcus aureus (MRSA). activity of zinc oxide nanoparticles against methicillin resistant Stap
Nanoscale 2018;10(10):4927-4939. https://doi.org/10.1039/c7nr08499d

15. Gray NA, Dhana A, Stein DJ, Khumalo NP. Zinc and atopic dermatitis: A systematic review and metaanalysis. J Eur Acad Dermatol Venereol 2019;33(6):1042-1050. https://doi.org/10.1111/jdv.15524
16. Zar HJ, Ehrlich RI, Workman L, Weinberg EG. The changing prevalence of asthma, allergic rhinitis and atopic eczema in African adolescents from 1995 to 2002. Pediatr Allergy Immunol 2007;18(7):560-565. atopic eczema in African adolescents from 1995

17. Steyn N, Eksteen G, Senekal M. Assessment of the dietary intake of schoolchildren in South Africa: 15 years after the first national study. Nutrients 2016;8(8):509. https://doi.org/10.3390/nu8080509

18. European Task Force on Atopic Dermatitis. Severity scoring of atopic dermatitis: The SCORAD index. Consensus Report of the European Task Force on Atopic Dermatitis. Dermatology 1993;186(1):23-31 https://doi.org/10.1159/000247298

19. Lewis-Jones MS, Finlay AY. The Children’s Dermatology Life Quality Index (CDLQI): Initial validation and practical use. Br J Dermatol 1995;132(6):942-949. https://doi.org/10.1111/j.1365-2133.1995. tb16953.x

20. Southern Africa Labour and Development Research Unit (SALDRU). National Income Dynamics Survey 2017. http://www.nids.uct.ac.za/documentation/questionnaires/wave-4 (accessed 27 May 2017).

21. Vaghri Z, Barr S, Wong H, Chapman G, Hertzman C. Age-based differences in hair zinc of Vancouver preschoolers. Biol Trace Elem Res 2008;126( Suppl 1):S21-S30. https://doi.org/10.1007/s12011-008-8215-7

22. Kumakli H, Duncan AV, McDaniel K, et al. Environmental biomonitoring of essential and toxic elements in hum salp bir using accerated microwave-assisted sample digestion and inductively coopled haman scalp har using accelerated microwave-assisted sample digestion and inductively coupled plasma optical emission

23. Mangiafico SS. Summary and analysis of extension program evaluation in R, version 1.18.1. 2016 rcompanion.org/handbook/ (pdf version: rcompanion.org/documents/RHandbookProgramEvaluation. pdf) (accessed 9 July 2019).

24. XE Currency Converter 1995 - 2019. https://www.xe.com/ (accessed 9 July 2019).

25. Ryabukhin YS. Activation analysis of hair as an indicator of contamination of man by environmenta trace element pollutants. International Atomic Energy Agency, report IAEA-RL-50. October 1976. http:// inis.iaea.org/search/search.aspx?orig_q=RN:35066075 (accessed 30 May 2017).

26. Lowe NM, Fekete K, Decsi T. Methods of assessment of zinc status in humans: A systematic review. Am Clin Nutr 2009;89(6):2040s-2051s. https://doi.org/10.3945/ajcn.2009.27230G

27. Di Toro R, Galdo Capotorti G, Gialanella G, Miraglia del Giudice M, Moro R, Perrone L. Zinc and copper status of allergic children. Acta Paediatr Scand 1987;76(4):612-617. https://doi. org/10.1111/j.1651-2227.1987.tb10530.x

28. el-Kholy MS, Gas Allah MA, el-Shimi S, el-Baz F, el-Tayeb H, Abdel-Hamid MS. Zinc and coppe status in children with bronchial asthma and atopic dermatitis. J Egypt Public Health Assoc 1990;65(56):657-668.

29. Kim E, Kim H, Kim J, Ko J, Yoo S, Ro Y. Hair zinc levels and efficacy of oral zinc supplementation Kim E, Kim H, Kim J, Ko J, Yoo S, Ro Y. Hair zinc levels and efficacy of oral zinc supplementation
in patients with atopic dermatitis. J Am Acad Dermatol 2014;70(5):AB63-AB63. https://doi. in patients with atopic derne

30. Zhou L, Leonard A, Pavel AB, et al. Age-specific changes in the molecular phenotype of patient with moderate-to-severe atopic dermatitis. J Allergy Clin Immunol 2019;144(1):144-156. https://doi org/10.1016/j.jaci.2019.01.015

31. National Department of Health, South Africa. Road to Health Book 2018. www.health.gov.za/index php/.../545-immunisation-survey?...road-to-health-booklet (accessed 2 July 2019).

32. Karabacak E, Aydin E, Kutlu A, et al. Erythrocyte zinc level in patients with atopic dermatitis and its relation to SCORAD index. Adv Dermatol Allergol 2016;33(5):349-352. https://doi.org/10.5114/ ada.2016.62841

33. Toyran M, Kaymak M, Vezir E, et al. Trace element levels in children with atopic dermatitis. J Investig Allergol Clin Immunol 2012;22(5):341-344.

34. Amin MN, Liza KF, Sarwar MS, et al. Effect of lipid peroxidation, antioxidants, macro minerals and trace elements on eczema. Arch Dermatol Res 2015;307(7):617-623. https://doi.org/10.1007/s00403-015$1570-2$

35. Jaryum KH, Okoye ZSC, Stoecker B. Hair zinc: An index for zinc status in under-five children from lowJaryum KH, Okoye ZsC, Stoecker B. Hair zinc: An index for zinc status in under-five children from low-
income communities in Kanam area of north-central Nigeria. Biol Trace Elem Res 2018;183(2):183-191. https://doi.org/10.1007/s12011-017-1133-9

36. Hennigar SR, Lieberman HR, Fulgoni VL 3rd, McClung JP. Serum zinc concentrations in the US population are related to sex, age, and time of blood draw but not dietary or supplemental zinc. J Nut 2018;148(8):1341-1351. https://doi.org/10.1093/jn/nxy105

Accepted 16 October 2019. 